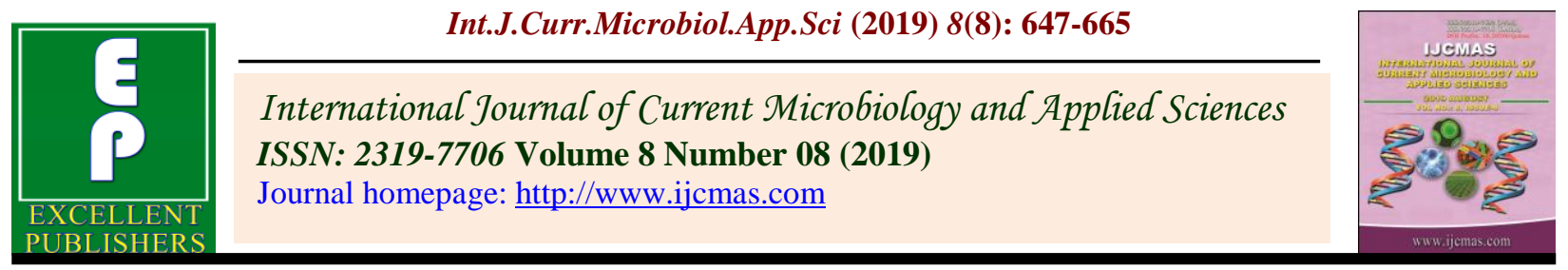

Original Research Article

https://doi.org/10.20546/ijcmas.2019.808.075

\title{
Clinicophysiological, Ultrasonographic and Histopathological Evaluation of 30 Cases in Cattle Suffering from Small Bowel Intussusception
}

\author{
Jagdeep Singh Mann*, Ashok Kumar, Hansraj Bharadwaj and Nawab Nashiruddullah
}

Department of Veterinary Surgery and Radiology, Shere-e-Kashmir University of Agricultural Sciences and Technology, R.S. Pura, Jammu- 181102, India

*Corresponding author

\begin{tabular}{l} 
K e y w o r d s \\
Clinicophysiological, \\
Ultrasonographic, \\
Histopathological, \\
Intussuscepted mass \\
\hline Article Info \\
\hline $\begin{array}{l}\text { Accepted: } \\
\text { 07 July } 2019 \\
\text { Available Online: } \\
\text { 10 August } 2019\end{array}$ \\
\hline
\end{tabular}

A B S T R A C T

The present study was conducted on 30 cattle presented at the institutional veterinary hospital which were diagnosed of suffering for the small bowel intussusception. Detailed signalment including age, sex, breed, pregnancy status and season were recorded in all the animals. History of feed and water intake, defecation status, rumination status, type of feeding, any recent change in feed, history of deworming and feeding of mineral mixture was also recorded.Clinical signs such as signs of colic, abdominal distension, rumen impaction, laboured breathing and ruminal bloat were accessed. Thorough physical examination was done in all animals to record rumen motility ( $2 / 3$ minute), rectal temperature $\left({ }^{\circ} \mathrm{F}\right)$, heart rate (beats/ $\mathrm{min}$ ), respiratory rate (breaths/ min), dehydration status, status of mucus membrane. Through Trans- rectal examination palpation of Intussuscepted mass, Status of rumen, colour and consistency of rectal contents were accessed. Ultrasonography of abdomen was done in 17 cases in which intussusception mass were not felt on trans-rectal examination for the lesions indicative of intussusception. Histopathological examination was done in all the 30 animals. For histopathology tissue samples were taken either just proximally or distally from surgically resected intussuscepted mass.

\section{Introduction}

Intussusception appears to be more common of all cases of intestinal obstruction in cattle (Chakrabarti, 2014). Intussusception is the invagination of a portion of the gastrointestinal tract into the lumen of an adjacent segment of bowel due to peristaltic movement and is often a cause of intestinal obstruction in cattle (Constable et al., 1997). Intussusception varies in duration and in the severity of clinical signs, which are associated with partial or complete gastrointestinal tract obstruction (Levitt and Bauer, 1992; Patsikas et al., 2008). Although the inciting cause is rarely identified, intussusception may occur secondary to enteritis, intestinal parasitism, sudden changes in diet, mural granuloma, or abscess, intestinal neoplasia (especially adenocarcinoma), mural hematoma, heavy 
work load and administration of drugs that affect intestinal motility (Archer et al., 1988; okomoto et al., 2007; Yadav et al., 2009; Milnes and McLachlan, 2015). Signs of pain are often transient with intussusception manifested by treading, stretching out and kicking at the abdomen (Fubini and Ducharme, 2004). Cattle show no interest in feed, eventually become dehydrated, slow abdominal distention, mass palpated per rectum; distended loops of intestine per rectum (Smith and Jones, 2009). History, clinical and clinicopathological examinations are important in the diagnosis of intussusception. Correct diagnosis at the earliest is very important to formulate the rational and effective therapeutic regimen. Intussusceptions require surgical correction, otherwise affected cattle die within 5 to 8 days (Constable et al., 1997). Scanning depth of ultrasonography is less than approximately 20 $\mathrm{cm}$ with a $3.5-\mathrm{MHz}$ transducer, or up to $30 \mathrm{~cm}$ with $2.5 \mathrm{MHz}$. Thus, the size of the abdomen precludes complete examination in larger animals (Streeter and Step, 2007).

Therefore, the purpose of this study was the early detection of intussusception based on history, clinical signs, physiological parameters and transrectal examination and also to evaluate age, sex, breed, type of feeding and season as risk factors for the development of intussusception in cattle, surgical management and postoperative outcome of affected cattle.

\section{Materials and Methods}

The present study was conducted on 30 cattle admitted to the department of Teaching Veterinary Clinical Complex (TVCC), Faculty of Veterinary Sciences and Animal Husbandry, Sher-e-Kashmir University of Agricultural Sciences and Technology, R.S. Pura, Jammu which were diagnosed of suffering for the small bowel intussusception based on history, clinical signs, trans rectal examination, ultrasonographic examination, exploratory laprotomy and followed by its confirmation through histopathological examination.

For the estimation of clinical signs and physiological parameters these thirty animals were divided into three equal groups containing 10 animals each depending upon the duration of intussusception since the first signs of colic appear viz. Animals showing signs of colic since 48 hours, more than 48 to $120 \mathrm{hrs}$ and more than 120 to 192 hours were assigned groups I, II and III, respectively. The data of physiological parameters of group I, II and III was also compared with the values obtained from the 6 healthy animals (control group) from the organised farm.

The various parameters viz.

\section{Anamnesis/Signalment}

Detailed signalment including age, sex, breed, pregnancy status and season were recorded in all the animals.

History of feed and water intake, defecation status, rumination status, type of feeding, any recent change in feed, history of deworming and feeding of mineral mixture was recorded in all the animals.

\section{Clinical signs}

Clinical signs such as colic signs, abdominal distension, rumen impaction, laboured breathing and ruminal bloat were accessed in all animals suffering from intussusception.

\section{Physiological parameters}

Thorough physical examination was done in all animals to record rumen motility (2/ 3 minute), rectal temperature $\left({ }^{\circ} \mathrm{F}\right)$, heart rate 
(beats/ min), respiratory rate (breaths/ min), dehydration status (based on skin tenting), colour/ status of mucus membrane (anaemic, congested or normal) was recorded.

\section{Trans rectal examination}

Trans- rectal examination was performed at the presentation of the case to the clinics. Intussuscepted mass: (Palpable/ not palpable),

Status of rumen: size (normal, distended, collapsed) and consistency (doughy, gas filled, hard, not palpable) of rumen was recorded during trans- rectal examination.

Colour of faeces/ rectal content was recorded as (normal, black tarry coloured, white mucoid rectal content or any other colour of rectal content).

Consistency of rectal content/ faeces was assessed in those cases where faeces was present in the rectum at the time of trans rectal examination and recorded as normal, pasty, or mucoid.

\section{Ultrasonographic examination}

Ultrasongraphy was performed only in those $17(56.67 \%)$ cases where intussusception mass was not palpated on trans-rectal examination. Ultrasonography was carried out using a concept/ MCV veterinary ultrasound scanner (Dynamic Imaging Livingston Scotland, U.K.) Ultrasound machine in real time B mode with a 3.5/ 5.0 MHz convex probe.

Ultrasonography was done in standing animal restrained in a crate without any sedation. The hair at the examination area was clipped. After the application of transmission gel to the transducer, the animals were examined. Abdomen was examined for distended intestinal loops, number of loops in one ultrasonographic field, movement of contents in intestinal loops, presence of peritoneal fluid in abdominal cavity, intestinal motility and any other lesion indicative of intussusception.

\section{Histopathological examination}

Histopathological examination was done in all the 30 animals. For histopathology tissue samples were taken either just proximally or distally from surgically resected intussuscepted mass. It was thoroughly washed with water and stored in $10 \%$ formalin solution for preservation. The tissue samples were routinely processed, sectioned to 4-5 $\mu \mathrm{m}$ thickness, stained with Hematoxylin and Eosin, and examined microscopically.

\section{Surgical treatment}

On the basis of history, clinical observations, ultrasonographic evaluation a tentative diagnosis was made. The tentative diagnosis was confirmed by exploratory laprotomy. Animal was restrained in standing position without sedation. The area on the right flank was prepared by shaving the area and thoroughly washing the area with water to remove the adhered hairs. The site was then scrubbed with aseptic solution in a routine manner. Then 2\% lignocaine hydrogen chloride was infiltrated @ $1 \mathrm{ml} / 1 \mathrm{~cm}$ in a linear fashion. Laparotomy was performed as per the standard procedure. Abdominal cavity was explored for intussuscepted mass and exteriorized from the abdominal cavity. End to end enteroanastomosis was performed after proper ligation of mesenteric blood supply. The ends of the intestine were sutured in two layers of inversion sutures.

\section{Statistical analysis}

The data generated was statistically analysed by using one-way ANOVA using SPSS (Statistical Package for Social Sciences) software (version 16.0-SPSS Inc.). 


\section{Results and Discussion}

\section{Anamnesis/Signalment}

\section{Age}

The age of affected cattle was $1-2$ years in 11 $(36.6 \%)$ cases, 2- 4 years in $18(60 \%)$ and $>5$ year in $1(3.33 \%)$ case. The mean age of all the thirty animals was $2.6 \pm 0.20$ years. The findings indicated that highest incidence was in 2-4 years of animals. Similarly, Dharmaceelan et al., (2012) reported that the incidence of intestinal obstruction was more in animals ranging from 2- 4 year of age. Dixit et al., (1975) also reported a higher incidence of intussusception in young calves aged between 1-2 years. The reason for more incidence of intussusception in 2-4 years of age in the present study is unknown, however, this may due to the fact that these animals were not lactating and so were offered poor feed and fodders (Table 1).

Moreover, our study also indicated that feed of these animals was not balanced as they were given improper mixture of green fodder and paddy/ wheat straw, un-chaffed fodder (in $50 \%$ of the cases) and there was no history of feeding of mineral mixture in any of the animal. In addition to it, none of these animals recorded to be dewormed against intestinal or other type of parasites. However, our findings are not in collaboration with Constable et al., (1997) who reported greater risk of developing small intestinal intussusception calves less than 2 months old than older cattle. Intussusception in cattle is rare except in young calves where it is often secondary to diarrhoea (Pearson, 1971). However, in present study no animal was below one year of age and reason for this could not be revealed. Additionally, Horne (1991) has reported that the age of the animal doesn't have any relation with the occurrence of intussusception in cattle.

\section{Breed}

All the animals were cross bred cattle, no case was recorded in Indian or zebu cattle (Bos indicus). Out of thirty, $21 \quad(70 \%)$ were Holstein Friesian cross and 9 (30\%) were Jersey cross. In the present study, higher incidence of small bowel intussusception in HF cross may be due to more population of this breed of cattle in the region. However, Dharmaceelan et al., (2012) observed a higher incidence of intestinal obstruction in Jersey cross breed $(50 \%)$ followed by HF cross (33.33\%). Constable et al., (1997) observed increased prevalence in Brown Swiss cattle relative to Holstein and decreased risk existed for Hereford cattle. No case was recorded in Indian cattle (Bos indicus) may be due to their better adaptability in Indian environment and inherited higher resistance against diseases.

\section{Sex}

All the thirty animals admitted were female. Similar, findings were also reported earlier (Braun et al., 2002; Dennison et al., 2002; Braun, 2005; Imran et al., 2011; Mestry et al., 2011). However, Constable et al., (1997) reported sex was not significantly associated with the cattle developing intussusception. The higher percentage of female animal in the present study could be related to more population of dairy animals in the region.

\section{Season}

Out of thirty clinical cases $10(33.33 \%)$ were admitted from July to September, 2016 (in monsoon/ rainy season) and remaining 20 $(66.67 \%)$ in the months of January and February, 2017 (winters). Maximum numbers of cases were recorded in winters. Similarly, Sharma et al., (2003) has also encountered all 22 cases of intestinal obstruction in their study only during winter season (November to February). Nuss et al., (2006) while treating 
ileal impaction in 22 cows investigated that the cause of the impaction was most likely due to seasonal influences and winter-feeding with hay based ration. On the other hand, Constable et al., (1997) reported season was not significantly associated with the cattle developing intussusception but a seasonal predilection may exist, because most intussusceptions reportedly develop in late winter and spring. Dharmaceelan (2012) also observed that season has no significant effect on the incidence of gastrointestinal obstructive disorders.

\section{Pregnancy status}

Nineteen (63.33\%) animals were nonpregnant, $6(20 \%)$ animals were in first trimester, $3(10 \%)$ animals were in second and $2(6.67 \%)$ animals were in third trimester of pregnancy. Maximum number of animals were non pregnant and intussusception does not seems to be related with pregnancy.

Dharmaceelan et al., (2012) found equal percentage of pregnant and non-pregnant animals in their study on gastro-intestinal obstruction. Many authors have reported disease in calves (Horne, 1991; Constable et al., 1997; Erol et al., 2015). However, Sharma et al., (2003) reported a higher incidence of intestinal obstruction in pregnant animals.

\section{Feed intake}

All the thirty animals were anorectic. Water intake was reduced in all the animals. Findings were similar to (Smart et al., 1977; Smith, 1985; Horne, 1991; Ortoloni et al., 1995; Constable et al., 1997; Karapinar and Kom, 2007; Hussain et al., 2015). Progressive anorexia and reduced water intake in all the animals could be due to intense colic initially followed by cessation of rumination, reduced extracellular fluid and dry mucus membrane as observed by (Papadopoulos et al., 1985 a).

\section{Type of feeding}

Overall the feeding management was poor. Type of feeding varied as per season. In summer or rainy season feed given was sorghum, green grass, maize and paddy straw/ wheat straw. In winters mostly berseem, oat and paddy straw. Concentrate feeding along with green fodder was recorded only in 5 $(16.66 \%)$ cases, which consisted of wheat bran, mustard cake and readymade feed. History of feeding paddy straw with or without green fodder was present in 27 (90\%) animals out of 30 and in very few cases 3 $(10 \%)$ there was history of wheat straw feeding. Intussusception was recorded on all type of feeds and does not seems to vary with type of feeding, however, Fubini and Ducharme (2004) stated that overeating on lush pasture can cause abnormal motility of intestine and may leads to development of intussusception (Table 2).

\section{Rumination status}

Rumination was also suspended in all 30 animals suffering from intussusception (as depicted in Table 3). Findings were similar to (Ortoloni et al., 1995). Papadopoulous (1985a) stated in experimental intestinal obstruction of cattle that the discontinuation of rumination was to be expected as the rumen was atonic.

\section{Any recent change in feed}

History of recent change in feed was present in $3(10 \%)$ animals out of 30 . In these animals there was sudden change in feeding just immediately before the animals started showing signs of colic. In one case change of feed was from sorghum to excessive quantity of paddy seedling, in second case change was from concentrates to green grass, in third case change in feed was from green fodder (sorghum, maize) to deoiled mustard cake and wheat bran. Occurrence of intussusception 
with sudden change in diet previously reported by (Pearson, 1971; Smith, 1985; Horne, 1991; Fubini and Ducharme, 2004; Desrochers and Anderson, 2016).

\section{Defaecation status/ Faecal output}

Defaecation was absent in all the animals. However, as per the history given by owners animals sometime passes small amount of black coloured grease like foul smelling faeces since the illness. At the time of presentation of case to the clinic very less amount that can stain the arm sleeve was present in 18 (60\%) cases.

These findings were similar to (Ortoloni et al., 1995; Constable et al., 1997; Karapinar and Kom, 2007; Hussain et al., 2015; Khalphallah et al., 2016. Smith (1980) stated that animal often pass faeces during the first few hours after intussusception as the distal part of the intestinal tract empties. Thereafter, the cow passes small amounts of sticky, dark red faeces that consist of blood from the mucosal surface of the intussusceptum mixed with mucus from the distal portions of the intestinal tract.

These faeces are sometimes described as having a raspberry jam appearance. Divers and Peek (2008) stated certainly faeces distal to the obstruction may be passed early in the course of intestinal obstruction, but in general cattle with small intestinal obstructions pass no faeces.

\section{Any previous history of intussusception}

In all the thirty animals intussusception occurred for the first time. There was no any previous history of intussusception in any of the animal. These findings are also depicted in Table 3. However, Pravettoni et al., (2009) reported repeated occurrence of jejuno- jejunal intussusception in a calf.

\section{History of deworming and mineral mixture feeding}

There was no history of deworming and mineral mixture feeding in any of the animal also depicted in Table 3. Parasitism is a cause of intussusception is reported by (Pearson, 1971; Smith, 1985; Horne, 1991; Desrochers and Anderson, 2016).

\section{Clinical signs}

\section{Signs of colic}

Colic signs were present in all animals of group I, II and III. Most pronounced sign was kicking at the abdomen (Fig. 1). Mostly occurred within first 12 hours however, in some cases colic was also noticed later on in the course of disease. Mostly the colic seen was mild in nature, however, in some cases severe colic was also noticed. Other signs of colic recorded were stamping of feet, arching of back, stretching of body by the animal, change in posture of the animal, frequent sitting and getting up by the animal, looking at the flank and animals standing with their hind legs stretched out.

Colic in intestinal obstruction was reported by many previous authors (Smart et al., 1977; Abutarbush and Naylor, 2006; Tyagi and Singh, 2010; Tharwat, 2011; Chakrabarti, 2014). Smith and Jones (2009) explained that colic is caused by the tension on the mesentery on the invaginating portion of the intestine. With time, ischemia of this portion leads to pain and eventually leads to loss of sensation. Distension of the intestine with fluid and gas proximal to the obstruction leads to abdominal pain. Allen et al., (1986) observed that the intensity of pain was probably proportional to the rapidity with which the intestinal tension developed and to the magnitude of the tension. Fubini and Ducharme (2004) stated if the strangulated tissue becomes nonviable, the 
pain may become less intense for a period of time if left untreated.

\section{Abdominal distension}

Overall abdominal distension was present in $23(76.66 \%)$ cases out of 30 cases. In group I, it was present in 6 animals out of 10 animals and abdominal distension was mild as compared to other groups. Abdominal distension was also noticed in 24 hour old or fresh cases. In group II, abdominal distension was present in 9 (90\%) animals out of 10 . In group III abdominal distension was present in $8(80 \%)$ animals out of 10 . Abdominal distension observed was of very severe nature in some of the cases of group III as compare to other groups.

These findings were similar to (Radostits et al., 2009; Tyagi and Singh, 2010; Tharwat 2011; Chakrabarti, 2014). Smith (1984) stated that abdominal distension in intussusception becomes apparent within hours of the onset of colic. This results from the accumulation of fluid and gas in the small intestine proximal to the obstruction. Similarly, the ventral sac of the rumen starts to enlarge as the movement of digesta from the rumenoreticulum into the omasum and abomasum slows. In later stages of the condition, the abdomen appears round (apple-shaped) because of massive distention in the stomach compartments and in the proximal jejunoileum.

However, abdominal distension was not observed in $7(23.33 \%)$ cases of the study. Similarly, abdominal distension was not observed in intussusception by (Karapinar and Kom, 2007; Erol et al., 2015; Khalphallah et al., 2016).

Smith and Jones (2009) stated that rumen usually shows no obvious distention and may have less filling than normal, especially when the duration of the disease is prolonged.

\section{Rumen impaction}

Rumen impaction was noticed in 5 (16.67\%) cases suffering from intussusception, out of five animals three were from group I, one from group II and one from group III. Rumen impaction in the present study did not vary with duration of the disease in the present study. Papadopoulos (1985a) observed occasional impaction of the ruminal contents in experimental intestinal obstruction. Khajuria (2009) also observed tense rumen on deep palpation in intussusception. In the present study, it may be due to hypomotility or atonicity of rumen in intussusception and poor quality of undigestible feed (Table 4).

\section{Laboured breathing}

Laboured breathing was present in 4 (13.33 $\%$ ) cases out of total 30 cases. Group wise it was present in one animal from group I, one animal from group II and two animals from group III. Normal respiration in intestinal obstruction was observed by (Smart et al., 1977; Horne, 1991; Karapinar and Kom 2007). However, abnormal respiration had also been observed by Abutarbush and Radostits (2004) on auscultation of lungs in a calf with intestinal obstruction found increased amplitude of lung sounds with laboured respiration and an expiratory grunt. Imran et al., (2011) also observed elevated respiratory rate and shallow respiration in intussusception. Anderson et al., (1993) observed tachypnea in intestinal obstruction. Fubini and Ducharme (2004) observed normal respiratory rate in intussusception unless the abdominal distension is severe. Papadopoulos (1985a) observed respiration depression in experimental intestinal obstruction in cattle and stated it may be due to the increased blood $\mathrm{pH}$. In our study all the animal were having history of drenching and open mouth respiration was seen in one animal immediately after faulty drenching of mustard 
oil. So laboured breathing in the present study could be related to faulty drenching.

\section{Ruminal bloat}

Ruminal bloat was present only in $1(3.33 \%)$ animal (group III) out of 30. It was noticed in animal of group. Ruminal tympany in intestinal obstruction was noted by (Pravettoni et al., 2009; Braun et al., 2011; Hussain et al., 2015). Pearson and Pinsent (1977) reported ruminal tympany in bovine suffering from intestinal obstructions and concluded this could be due to decreased ruminal motility.

Table.1 Signalments in animals suffering from intussusception

\begin{tabular}{|l|c|c|}
\hline Signalments & & No. of animals \\
\hline \multirow{4}{*}{ Age } & $<2$ years & $11(36.67 \%)$ \\
\hline \multirow{2}{*}{ Breed } & $2-4$ years & $18(60 \%)$ \\
\cline { 2 - 3 } & $>4$ years & $01(3.33 \%)$ \\
\hline \multirow{2}{*}{ Sex } & HF & $21(70 \%)$ \\
\cline { 2 - 3 } Season (months) & Jersey & $09(30 \%)$ \\
\cline { 2 - 3 } & Female & $30(100 \%)$ \\
\cline { 2 - 3 } Pregnancy & Mainy (July to Sept.) & 00 \\
\hline \multirow{3}{*}{ status } & Non pregnant & $10(33.33 \%)$ \\
\cline { 2 - 3 } & First trimester & $20(66.67 \%)$ \\
\cline { 2 - 3 } & Second trimester & $19(63.33 \%)$ \\
\cline { 2 - 3 } & Third trimester & $06(20 \%)$ \\
\hline
\end{tabular}

Table.2 Type of feed given to animals suffering from intussusception

\begin{tabular}{|c|c|c|c|c|}
\hline & \multicolumn{4}{|c|}{ TYPE OF FEEDING } \\
\hline & \multicolumn{2}{|c|}{$\begin{array}{l}\text { Green fodder with or } \\
\text { without Paddy/ Wheat straw }\end{array}$} & \multirow{2}{*}{$\begin{array}{l}\text { Concentrate } \\
\text { feeding with } \\
\text { Roughages }\end{array}$} & \multirow[t]{2}{*}{$\begin{array}{c}\text { Only Paddy } \\
\text { straw }\end{array}$} \\
\hline & $\begin{array}{l}\text { Sorghum, } \\
\text { Maize, Grass }\end{array}$ & $\begin{array}{c}\text { Berseem, } \\
\text { Oat }\end{array}$ & & \\
\hline No. of animals & 07 & 15 & 5 & 3 \\
\hline
\end{tabular}

Table.3 Anamnesis in animals suffering from intussusception

\begin{tabular}{|l|c|c|}
\hline \multirow{2}{*}{\multicolumn{1}{|c|}{ HISTORY }} & \multicolumn{2}{|c|}{ No. of Animals } \\
\cline { 2 - 3 } Feed intake & PRESENT & ABSENT \\
\hline Recent change in feed & $\mathbf{0 0}$ & $\mathbf{3 0}(\mathbf{1 0 0 \%})$ \\
\hline Rumination status & $\mathbf{0 3}(\mathbf{1 0 \%})$ & $\mathbf{2 7}(\mathbf{9 0 \%})$ \\
\hline Defaecation status & $\mathbf{0 0}$ & $\mathbf{3 0}(\mathbf{1 0 0 \% )}$ \\
\hline Previous history of intussusception & $\mathbf{0 0}$ & $\mathbf{3 0}(\mathbf{1 0 0 \%})$ \\
\hline H/o deworming & $\mathbf{0 0}$ & $\mathbf{3 0}(\mathbf{1 0 0 \% )}$ \\
\hline Mineral mixture & $\mathbf{0 0}$ & $\mathbf{3 0}(\mathbf{1 0 0 \%})$ \\
\hline & 00 & $\mathbf{3 0}(\mathbf{1 0 0 \%})$ \\
\hline
\end{tabular}


Table.4 Clinical signs observed in cattle suffering from Intussusception

\begin{tabular}{|l|c|c|}
\hline \multirow{2}{*}{\multicolumn{1}{|c|}{ Clinical signs }} & \multicolumn{2}{c|}{ No. of Animals } \\
\cline { 2 - 3 } & Present & Absent \\
\hline Signs of colic & $30(100 \%)$ & 00 \\
\hline Abdominal distension & $23(76.67 \%)$ & $07(23.34 \%)$ \\
\hline Rumen impaction & $05(20 \%)$ & $25(80 \%)$ \\
\hline Laboured breathing & $04(13.34 \%)$ & $26(86.87 \%)$ \\
\hline Ruminal bloat & $01(3.34 \%)$ & $29(96.67 \%)$ \\
\hline
\end{tabular}

Table.5 Physiological parameters recorded in healthy control animals and diseased animals suffering from intussusception (Mean \pm S.E)

\begin{tabular}{|l|l|l|l|l|l|}
\hline Parameter & $\begin{array}{l}\text { Control } \\
\text { group }(\mathbf{n = 6})\end{array}$ & $\begin{array}{l}\text { Group I } \\
(\mathbf{n = 1 0})\end{array}$ & $\begin{array}{l}\text { Group II } \\
(\mathbf{n = 1 0})\end{array}$ & $\begin{array}{l}\text { Group III } \\
(\mathbf{n = 1 0})\end{array}$ & $\begin{array}{l}\text { Reference } \\
\text { values }\end{array}$ \\
\hline Heart rate (/min) & $61.6 \pm 2.17^{\mathrm{a}}$ & $74.2 \pm 4.43^{\mathrm{a}}$ & $82.2 \pm 5.8^{\mathrm{b}}$ & $87.4 \pm 6.96^{\mathrm{c}}$ & $60-80$ \\
\hline Respiratory rate (/min) & $20.34 \pm 2.03$ & $24.8 \pm 1.72$ & $25.5 \pm 4.02$ & $28.1 \pm 3.49$ & $15-30$ \\
\hline Rectal temp. $\left(\mathbf{(}^{\mathbf{0}}\right)$ & $101.17 \pm 0.21^{\mathrm{a}} \mathrm{b}$ & $101.47 \pm 0.33^{\mathrm{b}}$ & $100.45 \pm 0.22^{\mathrm{ab}}$ & $99.79 \pm 0.68^{\mathrm{a}}$ & $101-102^{0} \mathrm{~F}$ \\
\hline Rumen motility & $3.00 \pm 00^{\mathrm{a}}$ & $1.2 \pm 0.39^{\mathrm{b}}$ & $0.7 \pm 0.34^{\mathrm{b}}$ & $0.4 \pm 0.22^{\mathrm{b}}$ & $(3 / 2 \mathrm{~min})$ \\
\hline Dehydration status (\%) & $5.17 \pm 0.17^{\mathrm{a}}$ & $6.8 \pm 0.25^{\mathrm{b}}$ & $6.8 \pm 0.29^{\mathrm{b}}$ & $8.2 \pm 0.44^{\mathrm{c}}$ & \\
\hline
\end{tabular}

Means bearing different superscripts differ significantly $(\mathrm{p}<0.05)$.

Table.6 Transrectal examination in animals suffering from intussusception

\begin{tabular}{|c|c|c|c|c|}
\hline \multicolumn{4}{|c|}{ Trans rectal examination } & No. of Animals \\
\hline \multirow{2}{*}{\multicolumn{2}{|c|}{ Intussusception mass }} & \multicolumn{2}{|c|}{ Palpable } & $13(43.33 \%)$ \\
\hline & & \multicolumn{2}{|c|}{ Not palpable } & $17(56.67 \%)$ \\
\hline \multirow[t]{7}{*}{ Status of rumen } & \multirow{4}{*}{\multicolumn{2}{|c|}{ Consistency }} & Doughy & $23(76.67 \%)$ \\
\hline & & & Hard & $04(13.33 \%)$ \\
\hline & & & Gas filled & $01(3.33 \%)$ \\
\hline & & & Not palpable & $02(6.67 \%)$ \\
\hline & \multirow[t]{3}{*}{ Size } & & Normal & $26(86.67 \%)$ \\
\hline & & & Distended & $02(6.67 \%)$ \\
\hline & & & Collapsed & $02(6.67 \%)$ \\
\hline \multirow{5}{*}{\multicolumn{2}{|c|}{ Colour of rectal contents }} & \multicolumn{2}{|c|}{ Greenish } & $04(13.33 \%)$ \\
\hline & & \multicolumn{2}{|c|}{ Raspberry jam } & $08(26.67 \%)$ \\
\hline & & \multicolumn{2}{|c|}{ White mucoid contents } & $06(20 \%)$ \\
\hline & & \multicolumn{2}{|c|}{ Varying colour } & $03(10 \%)$ \\
\hline & & \multicolumn{2}{|c|}{ Empty rectum } & $09(30 \%)$ \\
\hline \multirow{5}{*}{\multicolumn{2}{|c|}{$\begin{array}{l}\text { Consistency of rectal } \\
\text { contents }\end{array}$}} & \multicolumn{2}{|c|}{ Normal } & $03(10 \%)$ \\
\hline & & \multicolumn{2}{|c|}{ Firm } & $01(3.33 \%)$ \\
\hline & & \multicolumn{2}{|c|}{ Pasty } & $09(30 \%)$ \\
\hline & & \multicolumn{2}{|c|}{ Mucoid } & $08(26.67 \%)$ \\
\hline & & \multicolumn{2}{|c|}{ Empty rectum } & $12(40 \%)$ \\
\hline
\end{tabular}




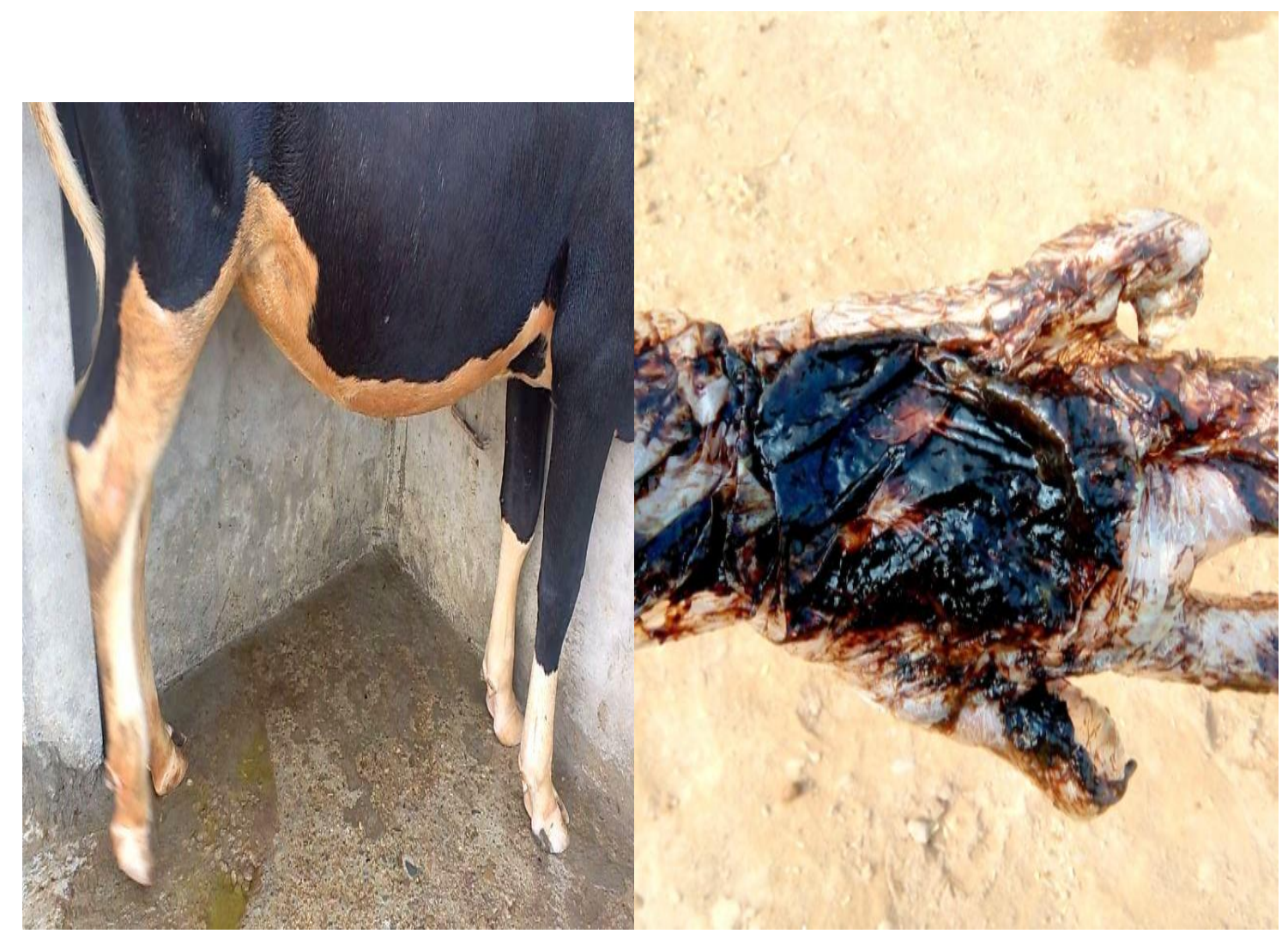

Fig 1: Abdominal kicking by animal

Fig. 2 Raspberry jam or tarry coloured contents

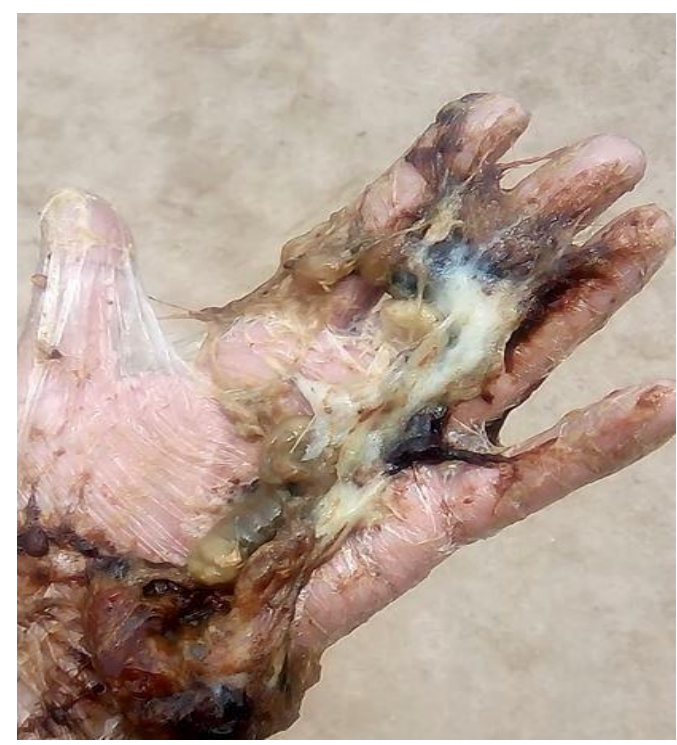

Fig 3: Mucoid rectal contents 


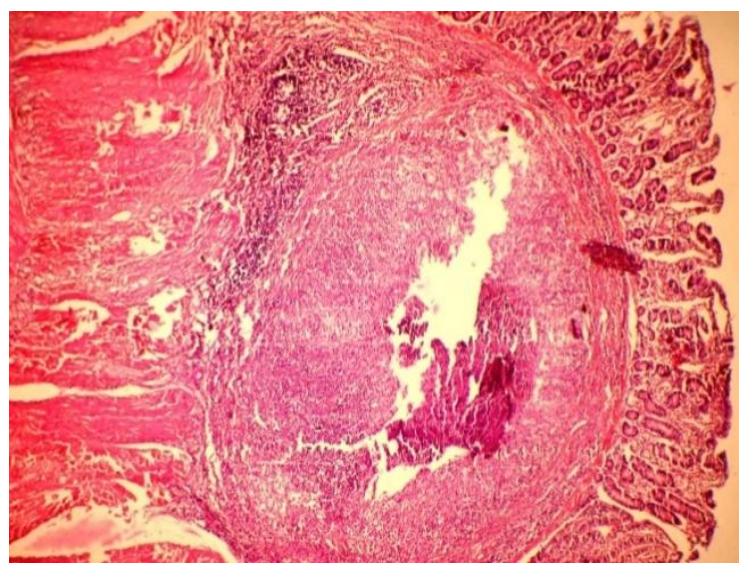

Fig 4: Solitary caseo-necrotic granulomatous lesion in the submucosa of the small intestine. Note the fibrous tissue encapsulation. $H \& E$ x 100

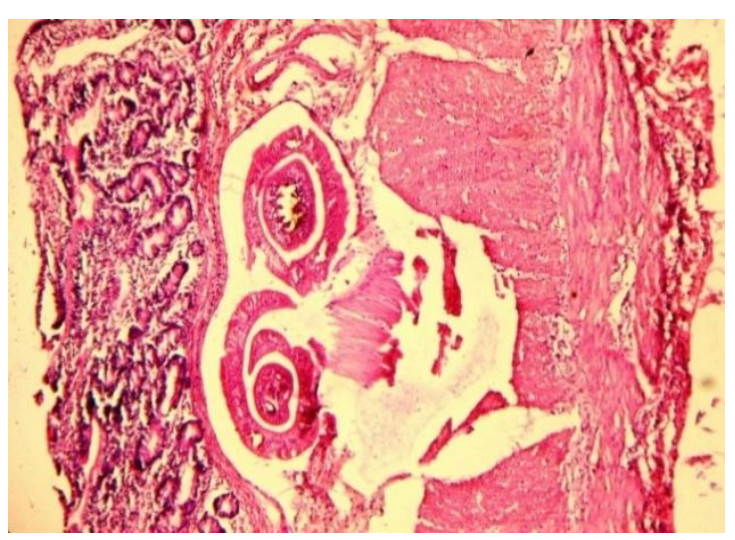

Fig 5: Cross section of nematode parasites in sub mucosa of small intestine. H\&E x 100

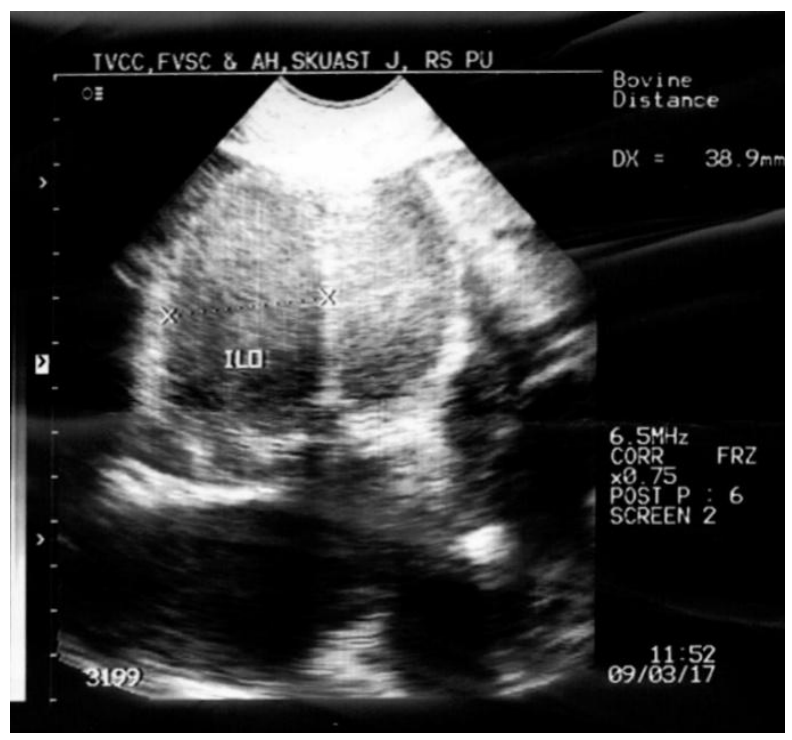

Fig 6: Dilated loops of intestine 


\section{Physiological parameters}

\section{Heart rate}

Mean \pm S.E. values of heart rate in group II and group III was found to be significantly higher than the control group while, the values were found to be comparable between control group animals and group I. Group I and group III also shown significant difference in heart rate. The heart rate of the affected animals was found to be slightly elevated initially, but as the chronicity of the cases developed (duration increases) the heart rate increased considerably. These findings were similar to (Imran et al., 2011). Tachycardia in intestinal obstruction was observed by (Horne, 1991; Anderson et al., 1993; Karapinar and Kom, 2007; Khalphallah et al., 2016). Radostits et al., (2009) stated increased heart rate might be due to the occlusion of blood vessels of intestinal part involved. This causes signs of endotoxic shock in animals including elevated heart rate, low blood pressure, muscular weakness and finally recumbency in animals with intussusception. However, Papadopoulos et al., (1985a) did not observed any significant change in heart rate during simple jejunal obstruction in cattle.

\section{Respiration rate}

Mean \pm S.E. values of respiration rate varied non significantly between all groups and it was found to be within normal physiological limits. Respiratory rate did not show a regular trend with respect to case history and results varied with respect to individual animal. Normal respiration was also observed in intestinal obstruction by (Pearson and Pinsent, 1977; Smart et al., 1977; Horne, 1991; Karapinar and Kom, 2007; Radostits et al., 2009). But in contrast to this finding Anderson et al., (1993) reported increase in respiration rate.

\section{Rectal temperature}

Mean \pm S.E. values of rectal temperature were not varied significantly among control group and diseased animal groups, whereas values were significantly different among group I and III. Mean \pm S.E. values of rectal temperature in group II and group III were slightly subnormal, whereas values of group I were lying in the normal range of healthy animal. Normal temperature was observed by (Smart et al., 1977; Anderson et al., 1993) whereas, subnormal temperature was recorded by (Papadopoulos et al., 1985a; Imran et al., 2011; Abutarbash and Radostits 2004). Steiner (2008) observed temperature of the body surface, especially the distal extremities, horns and ears are cooler than normal in intestinal obstruction. Hypothermia is attributed to development of severe dehydration in the late stages of intestinal obstruction (Papadopolous et al., 1985a).

\section{Rumen motility}

Mean \pm S.E. values rumen motility in all the groups of diseased animals was found to be significantly low from of control group animals. Group wise rumen motility was in descending from group I to group III, however statistically rumen motility not shown variation among diseased group animals. Rumen motility was nil in 4 cases of group I, 6 cases of group II and 7 cases of group III. In cases where rumen motility was present strength and amplitude was markedly less. Zavitz and Zavitz (1960) and Smart et al., (1977) observed complete absence of rumen motility in animals suffering from intussusception. Whereas, Abutarbush and Naylor (2006), Karapinar and Kom (2007) and Steiner et al., (2008) observed markedly reduced rumen motility in intestinal obstruction and sometimes rumen contractions persist but amplitude is decreased throughout the course of disease. 
Smith and Jones (2009) stated if pain is severe in obstruction, forestomach atony may occur. Reduced motility might be attributed to variable degree of distension in intussusception. The excessive distension by bulky ingesta may precipitate continuous activation of the epithelial receptors in forestomach lining leading to ruminal stasis, as it has a reflex inhibitory effect on primary cycle motility (Leek, 1983).

\section{Dehydration status}

Mean \pm S.E. values of dehydration status of all the groups of diseased animals showed significant variation from control. Group wise values of group I and group II varied significantly from group III. Dehydration was present in all the cases and it varied from $6 \%$ to $10 \%$. Dehydration in intussusception or intestinal obstruction was also noted by (Smart et al., 1977; Anderson et al., 1993; Abutarbush and Radostits, 2004; Steiner et al., 2008; Tharwat, 2011). The principal effect of dehydration can be explained on the basis of the loss of gastric and duodenal secretions by vomiting in intestinal obstruction (Hammond et al., 1964) and there were decreased or absence of water intake in the animals. Shields (1965) stated absorption from bowl immediately above obstruction hampered while secretions continue in normal amounts. Secretions accumulate in the bowel lumen and result in dehydration.

\section{Colour/Status of mucous membrane}

Normal colour (pink) of mucous membrane was recorded in $23(76.67 \%)$ cases and abnormal in $7(23.34 \%)$ cases. Out of abnormal mucus membranes, anaemic/ pale mucous membrane was seen in $4(13.33 \%)$ while congested mucous membrane was present in $3(10 \%)$ of the animals. All the 6 animals from control group were having normal colour of mucus membrane. Horne
(1991) and Abutarbush and Radostits (2004) found pale mucus membrane in animals with intestinal obstruction. Tharwat (2011) and Khalphallah (2016) reported congested mucus membrane in animals suffering from intussusception. Colour of mucous membrane is an indirect measurement of blood volume. Pale mucous membrane might be due to less blood volume or low haemoglobin level and congested mucus membranes might be due to presence of toxaemia (Table 5).

\section{Trans rectal examination}

Findings of transrectal examination in animals suffering from intussusception are depicted in Table 6.

\section{Intussuscepted mass palpation}

Intussuscepted mass was palpable transrectally only in $n=13(43.33 \%)$ cases and was not palpable in $17(56.67 \%)$ of the cases. Mass was not palpable in above 4 month pregnant animals. Distended loops of intestine were palpable in $20(66.67 \%)$ animals with or without the palpation of intussuscepted mass. In all the cases on palpation intussuscepted mass was firm and hard mostly present near pelvic brim but sometimes it was found in middle or right side of the abdomen. Constable et al., (1997) reported in 336 cases of cattle and intussuscepted mass was palpable in only minority of affected adult cattle $(23 \%)$ and the distended loops of the small intestine are palpable per rectum in only $50 \%$ of cases with the intussusception. Kushwaha et al., (2012) palpated intussuscepted mass per rectally in $13(65 \%)$ animals out of 20. Intussuscepted mass in this study was not palpated in advance pregnant animals. These findings were similar to those of (Imran et al., 2011 and Kushwaha et al., 2012). Smith (1990) also stated if the intussusception is located in the proximal jejunum, neither distended small intestine nor 
the lesion itself will be palpable and one may seriously doubt the diagnosis even if all other parameters indicate the presence of intussusception. Similarly, distended bowel may not be felt in cows that are in mid to late gestation because the uterus is pushed caudally and dorsally into the pelvic inlet. Radostits et al., (2009) also stated that intussusception mass is not always palpable and dependent on location of intussusception and the size of the animal.

\section{Status of rumen}

On trans-rectal examination, consistency of rumen was doughy in $22(73.33 \%)$, gas filled in $1(3.34 \%)$, hard in $5(16.67 \%)$ and not palpable in $2(6.67 \%)$. Size of rumen was normal in $26(86.67 \%)$ cases, distended in 2 $(6.67 \%)$ cases and was not palpable in 2 (6.67\%) cases. Khajuria (2009) also reported doughy consistency of rumen in cattle suffering from intussusception. Papadopoulos (1985a) observed occasional impaction of the ruminal contents in experimental intestinal obstruction. Distension of rumen was observed in many previous studies, Khajuria (2009) reported that rumen had reached almost to the brim of pelvic inlet in all the cows suffering from intussusception. Imran et al., (2011) found rumen, omasum and abomasum were markedly dilated extending beyond their normal topographic boundaries in six cattle suffering from intussusception. Tharwat (2011) on rectal examination in animals $(n=18)$ suffering from small intestinal obstruction revealed L-shaped distended rumen in four animals. Smith (1984) stated in intussusception ventral sac of the rumen starts to enlarge as the movement of digesta from the rumenoreticulum into the omasum and abomasum slows. Radostits et al., (2009) stated that in mature cattle that have been anorexic for several days, the rumen may be smaller than normal and the dorsal sac will be collapsed (rumen collapse) this may be the reason in the present study for collapsed rumen in two cases of group III. Abutarbush and Radostits (2004) observed gas distension of rumen in obstruction of small intestine caused by a hairball in 2 young beef calves.

\section{Colour and consistency of faeces/ rectal contents}

Colour of faeces varied from normal green colour in $4(13.34 \%)$ cases to black raspberry jam like faeces (Fig. 2) in 8 (26.67\%) cases, white coloured mucoid material in $6(20 \%)$ cases (Fig 3), rectal contents of varying coloured (mucus + blood mix) was noticed in 3 cases $(10 \%)$ and faeces were completely absent in remaining $9(30 \%)$ cases. Though rectum was empty in majority of the animals at the presentation of the case, but owner gave previous history of black coloured (raspberry jam like) faeces by the animals before they admitted into the clinic. Consistency of rectal contents was normal in $3(10 \%)$ cases, firm in $1(3.33 \%)$ pasty in $9(30 \%)$ cases, mucoid in $8(26.67 \%)$ ) cases and in remaining 9 (30\%) cases faeces was absent. Colour of faeces was normal green in fresh cases and in advance cases colour of faeces was black raspberry jam like or mucoid contents. Similarly, consistency of faeces/ rectal contents was also normal or firm in fresh cases and pasty where black tarry coloured faeces and sticky where mucoid rectal contents were present. Lack of defaecation in intussusception was observed by (Ortoloni et al., 1995; Constable et al., 1997; Abutarbush and Radostits, 2004; Karapinar and Kom 2007; Imran et al., 2011; Khalphallah et al., 2016). Kushwaha et al., (2012) observed empty rectum in all 20 cases suffering from intussusception, in recent cases they observed contents were very less in quantity and mixed with mucus plug, but in advanced cases, contents were tarry coloured. Smith (1980) noticed that faeces often continue to be passed 
during the first few hours after intussusception as the distal part of the intestinal tract empties. Thereafter, the cow passes small amounts of sticky, dark red faeces that consist of blood from the mucosal surface of the intussusceptum mixed with mucus from the distal portions of the intestinal tract. These faeces are sometimes described as having a raspberry jam appearance. Pravettoni et al., (2009) observed small quantity of dark, firm faeces containing sand-like material in the rectum of a 75 day old brown swiss calf suffering from intussusception. Scanty stools or mucus in the rectum was palpated on per rectal examination (Anderson et al., 1993; Tharwat et al., 2011). Zavitz and Zavitz (1960) observed dark blood streaked mucus in rectum. Fubini and Ducharme (2004) manure becomes scant or absent and in some cases melena is passed, presumably from sloughing of devitalized intestine mixed with mucus and faecal material.

\section{Gross and histopathological examination}

Histopathology was done in order to find the possible cause of intussusception and describe the underlying lesions. Besides, it also aided in the differentiation between segments of small intestine from the large intestine. Tissues for histopathology were taken either just proximal or distal to the intussuscepted mass. On the basis of gross and histopathological investigation, the primary cause $(66.67 \%)$ could be attributed to presence of intestinal parasitic nodules and granulomatous enteritis.

Grossly- The intestinal segments proximal or distal to the intussuscepted part appeared congested and oedematous. Small, nodular lesions were seen on the mucosal surface of the small intestine. Sometimes, long, slender worms were freely attached on the intestine and were tentatively identified as Setaria sp.
Histopathologically, parasitic cross sections could be demonstrated in the sub-mucosa of the intestine (Fig. 4). The parasites were enclosed in a fibrous tissue capsule with moderate tissue reaction. Parasites were often solitary or found in pairs. It was difficult to identify the parasites, but morphologically consistent with nematodes. In other sections, solitary to multiple granulomas could also be demonstrated. The granulomas were all surrounded by a fibrous tissue capsule with a central area of caseous necrosis (Fig. 5). Surrounding the caseous core, lymphocytes and an abundance of macrophages could be observed. The etiology of the granulomatous enteritis could not be ascertained, but presumably were due an inflammatory response against parasitic larvae/eggs as evident from other sections with demonstrable parasites. In some sections the lesions were consistent with chronic passive congestion and ischaemic necrosis. Severe congestion, sub mucosal edema, thrombosed blood vessels with degeneration of endothelium was observed. Occasionally, vacuolar degeneration of muscles was also seen. In some sections hyaline degeneration of intestinal muscles were prominent. Enteric lesions were characterized by hyperplastic Peyer's patches, sloughing of villi, and infiltration by inflammatory cells in the mucosa were also observed. Yousuf et al., (2011) observed necrosis and sloughing of epithelium, congestion and edema on histopathological examination in $(n=25)$ donkeys in which samples were taken from a distance of $10 \mathrm{~cm}$ proximal to the strangulated obstruction. Congestion and edema was also observed (khajuria, 2009; Wani, 2015). Parasitism is a cause of intussusception is reported by (Pearson, 1971; Smith, 1985; Horne, 1991; Desrochers and Anderson, 2016). Fubini and Ducharme (2004) stated nidus such as a small polyp or nodule in intestine causes aberrant intestinal motility and leads to intussusception. Radostits (2009) 
recorded a series in cows with intestinal polyposis: polyps in the mucosa dragged a section of intestine into an invagination in the next section. Smith and Jones (2009) stated most cases in adults were thought to be associated with an intramural mass or polyp. Oesophagostomum columbianum causes nodules in the intestinal wall of sheep but has not been proved to be linked to multiple deaths from intussusception. In contrast, in the young animals enteritis is often associated with intussusception.

\section{Ultrasonography}

Ultrasonography from the right side revealed dilated loops (Fig. 6) of small intestines ranges from $18 \mathrm{~mm}-52.2 \mathrm{~mm}$, passive movement of fluid, hyper-echoic intestinal wall and presence of peritoneal fluid. Intestinal contents were mostly echogenic in nature followed by hypoechoic or of anechoic echogenicity. Intestinal motility was found to be good in some cases, reduced in some cases and ileus in some cases. The present study being in agreement with previous reports Pravettoni et al., (2009) stated presence of dilated multiple loops of intestines in a single scanning area was also a prominent ultrasonographic finding in cases of intestinal intussusception.

Braun et al., (1995) stated this happens due to excessive entrapment of fluid and gases as well as ingesta in the lumen of the intestinal segments proximal to the site of the obstruction. However, such findings are not confirmatory to intestinal intussusception as these may be observed in any case of intestinal ileus. In the present study ultrasonography was performed only in those cases where intussusception mass was not palpated at trans-rectal examination 17 $(56.67 \%)$ and so "bull's eye" pattern was not recorded on transabdominal ultrasonography. The reason for this could be the scanning depth of ultrasonography is less than approximately $20 \mathrm{~cm}$ with a $3.5-\mathrm{MHz}$ transducer, or up to $30 \mathrm{~cm}$ with $2.5 \mathrm{MHz}$. Thus, the size of the abdomen precludes complete examination in larger animals (Streeter and Step, 2007) moreover, they also stated an intussusception may be visualized if located near the body wall, especially in young cattle or small ruminants, where relatively more of the abdomen can be imaged. Imran et al., (2011) in their study on 6 cross- bred cows suffered from intussusception reported that ultrasonography was not significantly helpful where transrectal examination of the cows did not reveal any suspected intestinal mass.

All animals were cross bred cattle. Disease was not recorded in Indian cattle (Bos indicus).

History of colicky pain was present in all the cases.

In all animals deworming was not done and there was no history of feeding mineral mixture in any of the animal.

There was no history of sudden change in feed or fodder in $27(90 \%)$ cases.

Intussuscepted mass was not palpable transrectally in animals above four month pregnant.

Paddy straw feeding was there in majority of the animals (except 3 out of thirty animals).

Histopathologically, the presence of parasites in intestinal sections and the observation of multiple caseo-granulomatous nodules. It is suggested that parasites and the tissue reaction against them may considerable interfere against maintenance of intestinal motility and may be the cause of intussusception. 


\section{References}

Abutarbush, S. M. and Naylor, J. M. (2006). Obstruction of the small intestine by a trichobezoar in cattle: 15 cases (19922002). Journal of American Veterinary Medical Association, 229: 1627-1630.

Abutarbush, S. M. and Radostits, O. M. (2004). Obstruction of the small intestine caused by a hairball in 2 young beef calves. The Canadian Veterinary Journal, 45(4): 324.

Allen, D., White, N. A. and Tyler, D. E. 1986. Factors for prognostic use in equine obstructive small intestinal disease

Anderson, D. E., Constable, P.D. and St-jean, G. (1993). Small intestinal volvulus in cattle: 36 cases (1961- 1993). Journal of American Veterinary Medical Association, 203: 1178-83.

Archer, R. M., Cooley, A. J. and Hinchcliff, K. W. (1988). Jejunojejunal intussusception associated with a transmural adenocarcinoma in an aged cow. Journal of the American Veterinary Medical Association, 192: 209-11.

Braun, U. (2005). Ultrasound as a decisionmaking tool in abdominal surgery in cows. Veterinary Clinics of North America: Food Animal Practice, 21: 3353.

Braun, U., Amrein, E., Koller, U. and Lischer, C. (2002). Ultrasonographic findings in cows with silatation, torsion and retroflexion of the caecum. The veterinary Record, 150: 75- 79.

Braun, U., Marmier, O. and Pusterla, N. (1995). Ultrasonographic examination of the small intestine of cows with ileus of the duodenum, jejunum or ileum. The Veterinary Record, 137(9): 209-215.

Braun, U., Schnetzler, C., Previtali, M., Gerspach, C. and Schmid, T. (2011). Duodenal ileus caused by a calf feeding nipple in a cow. Bio Med Central Veterinary Research, 7: 2.

Chakrabarti, A. (2014). Textbook of Clinical Veterinary Medicine, $4^{\text {th }}$ Edition Kalyani publishers, Ludhiana. pp. 286- 353.
Constable, P. D., Jean, S. G., Hull, B.L., Rings, D.M., Morin, D.E. and Nelson, D.R (1997). Intussusception in cattle: 336 cases (1964-1993). Journal of American Veterinary Medical Association, 210: 531-536.

Dennison, A. C., Vanmetre, D. C., Callan, R. J., Dinsmore, P., Mason, G. L. and Ellis, R. P. (2002). Haemorrhagic bowel syndrome in dairy cattle: 22 cases (1997-2000). Journal of American veterinary medical association, 221: 1149.

Desrochers, A. and Anderson, D. E. (2016). Intestinal Surgery. Veterinary Clinics of North America: Food Animal Practice, 32: 645-671.

Dharmaceelan, S., Rajendran, N., Nanjappan, K., Subramanian, M. and Balasubramaniam, G. A. (2012). Incidence of bovine gastrointestinlal obstruction in a Teaching Veterinary Hospital of Tamilnadu, India. International Journal of Veterinary Sciences, 1(3): 112-114.

Divers, T. Z. and Peek, S. F. (2008). Rebuhn's diseases of dairy cattle, $2^{\text {nd }}$ Edition Saunders Elsevier, St. Louis, Missouri. pp. 130- 199.

Dixit, S. N., Sadana, R. and Arora, R. G. (1975). Intussusception in young animals: a report of five cases. Haryana Veterinarian, 14: 21-22.

Doll, K., Klee, W. and Dirksen, G. (1998). Cecal intussusception in calves. Tierarzthliche praxis, ausgabe $G$, grosstiere/nutztiere. 26(5): 245-53.

Erol, M., Koç, Y., Altan, S. and Erol, H. (2015). Surgical treatment of a calf with jejunum intussusception: Case report. Eurasian Journal of Veterinary Sciences, 31(1): 6062.

Fubini, S. L. and Ducharme, N. G. (2004). Farm Animal Surgery, $9^{\text {th }}$ Edition Saunders, Elsevier, pp. 161-240.

Hammond, P. B., Dziuk, H. E., Usenik, E. A and Stevens, C. E. (1964). Experimental intestinal obstruction in calves. Journal of Comparative Pathology, 74: 210- 222.

Hussain, S. A., Uppal S. K., Randhawa, C. S. 
and Sood, N. K. (2015). Bovine intestinal obstruction: blood gas analysis, serum $\mathrm{C}$ reactive protein and clinical, haematological and biochemical alterations. Journal of Applied Animal Research, 43(2): 224-230.

Imran, S., Tyagi, S. P., Kumar, A., Kumar, A., Sharma, A. and Shivali, S. (2011). Usefulness and limitation of ultrasonography in the diagnosis of intestinal intussusception in cows. Veterinary Medicine International, 2011: 584387. doi:10.4061/2011/584387.

Karapinar, T. and Kom, M. (2007). Transrectal ultrasonographic diagnosis of the intussusception in a cow-case report special. Irish Veterinary Journal, 60: 7.

Khajuria, S. (2009). Studies on pre and postoperative haematobiochemical, blood gas and plasma mineal status in cows with intestinal obstruction. M.V.Sc thesis, Sher-e-Kashmir University of Agricultural Sciences and Technology, Jammu, India.

Khalphallah, A., Aref, N. M., Elmeligy, E. and EL-Hawari, S. F. (2016). Clinical and ultrasonographic observations of functional and mechanical intestinal obstruction in buffaloes (Bubalus bubalis). Veterinary World, 9(5): 475480.

Kushwaha, R. B., Gupta, A. K., Bhadwal, M. S., Bhadwaj, H. R, Tripati, A. K. and Shard, K. (2012). Intestinal obstruction due to intussusception in cattle: a clinical study of twenty cases. Indian Journal of Veterinary Science, 33(1): 63-65.

Leek, B. F. (1983). Clinical diseases of the rumen: A physiologist's view. Veterinary Record, 113: 10- 14.

Levitt, L. and Bauer, M. S. (1992). Intussusception in dogs and cats: A review of 36 cases. Canadian Veterinary Journal. 33: 660-664.

Mestry, G. R., Patel, P. B., Patel, J. B., Mistry, J. N. and Suthar, D. N. (2011). Intestinal obstructions in bovines and its surgical management-A clinical report of 12 cases. Intas Polivet, 12: 308-312.
Miller, G. R. and Schelkopf, S. L. (1959). Temporary Enterostomy in the correction of intestinal intussusception. Iowa State University Veterinarian, 21 (2): 91-93.

Milnes, E. L and McLachlan, A. (2015). Surgical management of small intestinal intussusception associated with jejunal adenocarcinoma in a dairy cow. Newzealand Veterinary Journal, 63: 28890.

Nuss, K., Lejeune, B., Lischer, C. and Braun, U. (2006). Ileal impaction in 22 cows. The veterinary journal, 171: 456- 61.

Okamoto, M., Itoh, H. and Koiwa, M. (2007). Intussusception of the spiral colon associated with fibroserous granulation in a heifer. Veterinary Record, 160: 376-8.

Ortolani, E. L., July, R. J. and Feitosa, L. F. (1995). A rare case of intussusception in a dairy cow. Brazalian Journal of Veterinary Research Animal Science, 32(1): 27-30.

Papadopolous, P., Raptopouloas, D., Dessiris, A. and Tsimopoulos, G. (1985a). Experimental Intestinal Obstruction in Cattle Part: Changes in the clinical picture. Zentralblatt Fur Veterinarmedizin Reihe A (Journal of Veterinary Medicine), 32: 264-275.

Patsikas, M. N., Papazoglou, L. G. and Adamama-Moraitou, K. K. (2008): Spontaneous reduction of intestinal intussusception in five young dogs. Journal of the American Animal Hospital Association, 44: 41-47.

Payton, J. (1954). Perforating duodenal sarcoma and intussusception in a cow. Journal of the American Veterinary Medical Association, 124: 351-2.

Pearson, H. (1971). Intussusception in cattle. Veterinary Record, 89: 426-437.

Pearson, H. and Pinsent, H. J. (1977). Intestinal obstruction in cattle. Veterinary Record, 101: 162-166.

Pravettoni, D., Morandi, N., Rondena, M., Riccaboni, P., Zani, D, D., Scandella, M. and Belloli, A.G. (2009). Repeated occurrence of jejuno-jejunal intussusception in a calf. Canadian 
Veterinary Journal, 50: 287-290.

Sharma, A., Kumar, U., Gupta, A. and Ryot, K. D. (2003).Clinical observations in intestinal obstruction in cattle- a field study of 12 cases. Indian Veterinary Journal, 80: 265-267.

Shields, R. (1965). The absorption and secretion of the fluid and electrolytes by the obstructed bowel. Brtish Journal of Surgery. 52: 774.

Silva Filho, A. P., Afonso, J.A.B. and Souza, J.C.D.A. (2010). Clinical and pathological analysis in 20 cases of intussusception in cattle. Veterinaria $e$ Zootecnia, 17: 422-31 [in Portuguese].

Smart, M. E., Fretz, P. B., Gudmundson, J. and Cymbaluk, N. (1977). Intussusception in a charolais bull. Canadian Veterinary Journal, 18: 244-246.

Smith, D. F. (1985). Bovine intestinal surgery. Part 5. Modern Veterinary Practice, 66: 405-409.

Smith, D. F. (1990). Surgery of the Bovine Small Intestine. Veterinary Clinics of North America: Food Animal Practice, 6(2): 449- 460.

Smith, D.F. (1980). Intussusception in adult cattle. Compendium on Continuing Education for the Practising Veterinarian Vet II: S49-S53

Smith, D.F. (1984). Bovine intestinal surgery. Part 3. Modern Veterinary Practice, 65: 909-914.

Smith, P. B. and Jones, L. S. (2009). Diseases of alimentary tract. In: Smith, P.B. (ed.). Large Animal Internal Medicine $4^{\text {th }}$ Edition Mosby, Elsevier St. Louis, Missouri. pp. 779-892.
Steiner, S., Krametter-Frötscher, R. and Baumgartner, W. (2008). Obstruction of the intestine in adult cattle. Wiener Tierarztliche Monatsschrift, 95(7): 166176.

Streeter, R. N. and Step, D.L. (2007). Diagnostic ultrasonography in ruminants. Veterinary Clinics: Food Animal practice, 23: 541-574.

Tharwat, M. (2011). Diagnostic ultrasonography in cattle and buffaloes with intestinal obstruction. Journal of Agriculture and Veterinary Science, 4: 67-80.

Tyagi, R. P. S. and Singh, J. (2010). Ruminant Surgery. $1^{\text {st }}$ Edition CBS publishers, India. pp 183- 224.

Wani, R. A. (2015). Ultrasonographic studies on surgical affections of gastrointestinal tract in bovine. M.V.Sc thesis, Sher-eKashmir University of Agricultural Sciences and Technology, Jammu, India.

Yadav, G. U., Bhikane, A. U. and Aher, V. D. (2009). Standardization of diagnostic procedures and operative methodology in clinical cases of intussusception in bovines. Intas Polivet, 10: 4-7.

Yousuf, H. A., Ali, M. M. and Kuraa, H. M. M. (2011). Effect of small intestine strangulation obstruction on clinical and histopathological parameters an experimental study on donkeys. Veterinary Research Forum, 2(2): 75-86.

Zavitz, S. and Zavitz, V. (1960). Rumenotomy \& intestinal anastomosis in a heifer. Canadian Veterinary Journal, 1(3): 115118.

\section{How to cite this article:}

Jagdeep Singh Mann, Ashok Kumar, Hansraj Bharadwaj and Nawab Nashiruddullah. 2019. Clinicophysiological, Ultrasonographic and Histopathological Evaluation of 30 Cases in Cattle Suffering from Small Bowel Intussusception. Int.J.Curr.Microbiol.App.Sci. 8(08): 647-665. doi: https://doi.org/10.20546/ijcmas.2019.808.075 